\title{
Effect of Continuous Positive Airway Pressure on Overactive Bladder Symptoms in Patients with Obstructive Sleep Apnea Syndrome
}

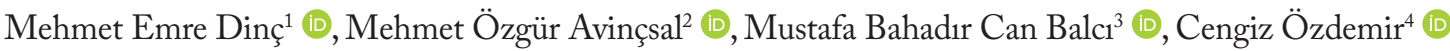 \\ ${ }^{1}$ Department of Otolaryngology - Head and Neck Surgery, Okmeydanı Training and Research Hospital, İstanbul, Turkey \\ ${ }^{2}$ Department of Otolaryngology - Head and Neck Surgery, İstanbul Gaziosmanpaşa Taksim Training and Research Hospital, \\ İstanbul, Turkey \\ Original Investigation \\ ${ }^{3}$ Department of Urology, İstanbul Gaziosmanpaşa Taksim Training and Research Hospital, İstanbul, Turkey \\ ${ }^{4}$ Sleep Disorders Clinic, Yedikule Chest Disease and Thoracic Surgery Training and Research Hospital, İstanbul, Turkey
}

\begin{abstract}
Objective: To evaluate overactive bladder $(\mathrm{OAB})$ in male and female patients with moderate or severe obstructive sleep apnea syndrome (OSAS) and to investigate the impact of three months of continuous positive airway pressure (CPAP) therapy on the symptoms of OAB.

Methods: Twenty-eight female and 45 male patients with moderate and severe OSAS whose obstructive sleep apnea (OSA) severity was evaluated according to the apnea-hypopnea index were included in the study. Patients' voiding symptoms were evaluated using the validated Turkish translations of overactive bladder symptom scores (OAB-V8) and the International Consultation on Incontinence Questionnaire Short-Form (ICIQ-SF) at OSAS diagnosis and at 3-months after the CPAP therapy.
\end{abstract}

Results: Patients with moderate and severe OSAS were more likely to have $\mathrm{OAB}$ than the average population, and CPAP therapy improved the symptoms of $\mathrm{OAB}$ in both male and female patients. In addition, a positive association was observed between OSA severity and $\mathrm{OAB}-\mathrm{V} 8$ and ICIQ-SF in female patients and between OSA severity and OAB-V8 in male patients.

Conclusion: Our findings suggest that CPAP therapy improves the clinical symptoms of OAB. Thus, unnecessary medical or interventional treatment of $\mathrm{OAB}$ can be avoided in such patients.

Keywords: Obstructive sleep apnea syndrome, overactive bladder, continuous positive airway pressure, treatment
ORCID IDs of the authors: M.E.D. 0000-0002-9931-8961; M. O..A. 0000-0002-3896-5807; M.B.C.B. 0000-0003-0395-1154; C..0. 0000-0002-9816-8885

Cite this article as: Dinç ME, Avinçsal MÖ, Balc MBC, Özdemir C. Effect of Continuous Positive Airway Pressure on Overactive Bladder Symptoms in Patients with Obstructive Sleep Apnea Syndrome. Turk Arch Otorhinolaryngol 2018; 56(3): 133-8.

\section{Corresponding Author:} Mehmet Emre Dinç; dremredinc@hotmail.com

Received Date: 23.01 .2018 Accepted Date: 25.04.2018

๑ Copyright 2018 by Official Journal of the Turkish Society of Otorhinolaryngology and Head and Neck Surgery Available online at www.turkarchotolaryngol.net DOl: 10.5152/ta0.2018.3251

\section{Introduction}

Obstructive sleep apnea syndrome (OSAS) is a common sleep-related breathing disorder. Moderate to severe obstructive sleep apnea (OSA) affects $2 \%-14 \%$ of the general population (1). OSA is a repetitive episode of upper airway collapse occurring during sleep that leads to intermittent hypoxia, hypercapnia, increased respiratory effort, sleep fragmentation, and increased sympathetic activity. It is commonly associated with cardiovascular and metabolic complications (2). Several studies have reported a relationship between OSA and urologic dysfunctions (3, 4). Earlier studies have also observed a positive association of OSAS with overactive bladder (OAB) as well as a correlation between the severity of OSAS and OAB in both men and women $(3,4)$.

Overactive bladder is defined as a urinary urgency with or without urge incontinence in the absence of a proven infection or an obvious pa- thology. Affected individuals often experience increased daytime frequency and nocturia. The key symptom is urinary urgency, which is a sudden irresistible desire to void that is difficult to delay. Despite extensive study, the etiopathogenesis of $\mathrm{OAB}$ remains unclear. The diagnosis of $\mathrm{OAB}$ requires the assessment of patient's clinical symptoms while excluding other conditions (5). $\mathrm{OAB}$ has a considerable influence on the quality of life (QoL) of patients. Patients with $\mathrm{OAB}$ limit their physical activity and participation in social events, which leads to anxiety and depression. $\mathrm{OAB}$ can also cause urinary tract infections, which increases the number of healthcare visits. Treatment options range from lifestyle modifications to interventional therapy; however, the outcomes remain unsatisfactory. The efficacy of medical therapy is limited by potential side effects and poor responses. Despite several alternative treatment options being available, the outcomes remain poor (6). 
Continuous positive airway pressure (CPAP) therapy remains the standard treatment for confirmed cases of OSA (7). Although studies have shown an association between OSA and $\mathrm{OAB}$ in both men and women, the impact of CPAP therapy on the symptoms of $\mathrm{OAB}$ remains unclear. In this study, we evaluated $\mathrm{OAB}$ in male and female patients with moderate or severe OSA and evaluated the impact of three months of CPAP therapy on the symptoms of OAB.

\section{Methods}

\section{Study design}

This prospective study was conducted in the Department of Otorhinolaryngology of the Gaziosmanpaşa Taksim Training and Research Hospital, Istanbul, Turkey, and approved by the local ethics committee (Approval no: 12/10.06.2015). The study adhered to the tenets of the Declaration of Helsinki. Polysomnography (PSG) was performed in the Sleep Laboratory of Yedikule Chest Disease and Thoracic Surgery Training and Research Hospital, Istanbul, Turkey. Written informed consent was obtained from all participants for their participation in the study.

\section{Participants}

Male and female patients were divided into two groups, and each group was separately evaluated. Patients with neurological disorders (e.g., multiple sclerosis, diabetes insipidus, disk herniation, dementia, and stroke), diabetes mellitus, congestive heart failure, previous urogenital operations, renal dysfunction, physical disability, active urinary tract infection, urolithiasis, interstitial cystitis, or urinary retention were excluded, as were those who were taking hypnotic, diuretic, or anticholinergic medications.

\section{Polysomnography}

Obstructive sleep apnea was diagnosed on the basis of fullnight PSG in the sleep laboratory using a digital PSG system (Compumedics E Series platform, Compumedics, Melbourne, Australia). A certified PSG technologist scored all recordings under the guidance of a sleep physician. Sleep levels and the apnea-hypopnea index (AHI) were determined according to the recommendations of the American Academy of Sleep Medicine Task Force (8). Apnea was confirmed if at least a 90\% cessation of airflow from baseline, continuing for a minimum of $10 \mathrm{~s}$, was observed, and hypopnea was confirmed if at least a $30 \%$ reduction in the airflow, continuing for a minimum of 10 s, was observed and associated with an at least $4 \%$ reduction in arterial oxyhemoglobin saturation. Apneas were identified as obstructive if respiratory efforts were present and as central if respiratory efforts were absent. AHI was defined as the sum of the number of apneas and hypopneas per hour of sleep time, and the severity of OSA was defined using the following AHI cutoffs: simple snoring, AHI $<5$; mild OSA, $5 \leq \mathrm{AHI}<15$; moderate $\mathrm{OSA}, 15 \leq \mathrm{AHI}<30$; and severe $\mathrm{OSA}, \mathrm{AHI} \leq 30$. CPAP titration was performed using a mask and a suitable apparatus (Respironics Inc., Murrysville, PA, USA). Ideal pressure is defined as the pressure that enables a patient to have a stable rapid eye movement sleep in the supine position while maintaining oxygen saturation without snoring, demonstrating no variability in the heart rate, and exhibiting no arousal. After CPAP therapy at home for three months, patients were required to complete the questionnaires again.

\section{Questionnaires}

All patients were required to complete the validated Turkish translations of overactive bladder symptom scores (OAB-V8) (9) and the International Consultation on Incontinence Questionnaire Short-Form (ICIQ-SF) (10).

Patients completed the self-report questionnaires twice at baseline examination after the diagnosis of OSA and three months after CPAP therapy via telephone.

The OAB-V8 is an 8-item questionnaire that is used to monitor $\mathrm{OAB}$, including the symptoms of daytime and nighttime frequencies, urgency, and urge incontinence. The questions were created to assist patients and health professionals to identify the symptoms of $\mathrm{OAB}$. Scores range from 0 to 40 points. $\mathrm{OAB}$ is defined as a score of $\geq 8$ points on $\mathrm{OAB}-\mathrm{V} 8$.

The ICIQ-SF is a 4-item questionnaire that evaluates urinary continence. Items assess the frequency of urinary incontinence (UI), perceived amount of UI, and the influence on QoL. Scores range from 0 to 21 points.

In addition to these questionnaires, male patients responded to the International Prostate Symptoms Score Questionnaire (IPSS) (11) to exclude prostate problems. The IPSS is a commonly used standardized 8-item questionnaire that assesses the symptoms of benign prostate hyperplasia. Scores range from 0 to 35 points.

\section{Statistical Analysis}

Mean; standard deviation; and median, minimum, and maximum were calculated for descriptive statistics. The Mann-Whitney $\mathrm{U}$ test, marginal homogeneity test, Wilcoxon signed rank test, Fisher's exact test, and Pearson chi-square tests were used. Number Cruncher Statistical System 2007 software (NCSS, Kaysville, UT, USA) was used for all analyses.

\section{Results}

A total of 28 female and 45 male patients were included in this study. OSA severity was determined on the basis of PSG. The return rate for questionnaires was $100 \%$. The demographic characteristics of all patients and controls are shown in Table 1.

\section{Female OSA group}

A total of 20 (71.4\%) patients had severe OSA and eight (28.6\%) had moderate OSA. There were no significant differences with respect to age between patients with moderate and severe OSA $(\mathrm{p}>0.05)$.

There were no significant differences in the prevalence of $\mathrm{OAB}$ [6 patients $(75.0 \%)$ vs. 17 patients $(85.0 \%), \mathrm{p}>0.05$ ] between 
patients with moderate and severe OSA before CPAP therapy. Similarly, there were no significant differences in OAB-V8 median [15 (1016.5) vs. 16 (1221.5), p>0.05] between patients with moderate and severe OSA before CPAP therapy. When pre- and post-therapy parameters were compared to evaluate the effects of CPAP therapy, significant differences in OAB-V8 were noted between patients with moderate and severe OSA. The median OAB-V8 was significantly lower in patients with moderate [15 (1016.5) vs. 9 (711.5), $\mathrm{p}=0.035]$ and severe [16 (1221.5) vs. 10.5 (712.5), $\mathrm{p}<0.001]$ OSA after CPAP therapy than before the therapy. The prevalence of OAB was lower in patients with moderate [6 patients $(75.0 \%)$ vs. 5 patients (62.5\%), $\mathrm{p}=0.317$ ] and severe [17 patients $(85.0 \%)$ vs. $14 \mathrm{pa}^{-}$ tients (70.0\%), $\mathrm{p}=0.083$ ] OSA after CPAP therapy, but the difference was not statistically significant (Table 2). In addition, correlations between $\mathrm{AHI}$ and $\mathrm{OAB}-\mathrm{V} 8$ and ICIQ-SF were also explored, which revealed a significant positive correlation between $\mathrm{AHI}$ and OAB-V8 $(\mathrm{r}=0.516, \mathrm{p}=0.005)$ and ICIQ-SF $(\mathrm{r}=0.497, \mathrm{p}=0.007)$ (Table 3).

\section{Male OSA group}

A total of 32 (71.1\%) patients had severe OSA and 13 (28.9\%) had moderate OSA. There were no significant differences with respect to age between patients with moderate and severe OSA. There was a significant difference in the prevalence of $\mathrm{OAB}$ [5 patients $(38.5 \%)$ vs. 24 patients $(75.0 \%), p=0.037$ ] between patients with moderate and severe OSA before CPAP therapy, whereas there was no significant difference in OAB-V8 median (6 [413] vs. 12.5 [714], $p>0.05)$ between patients with moderate and severe OSA before CPAP therapy. When the parameters were compared before and after CPAP therapy, significant differences between the prevalence of OAB $\left[24 \mathrm{pa}^{-}\right.$ tients (75.0\%) vs. 19 patients (59.4\%), $\mathrm{p}=0.025]$ and $\mathrm{OAB}-\mathrm{V} 8$ median [12.5 (714) vs. 10 (612), $\mathrm{p}<0.001]$ were observed in

Table 1. Comparison of patients' characteristics

\begin{tabular}{l|c|c|c|c|c|c|c|}
\hline & \multicolumn{3}{|c|}{ Female (n=28) } & & \multicolumn{2}{c}{ Male (n=45) } \\
\hline & Moderate & Severe & p & Moderate & Severe & p \\
\hline Age years & $52(49,54.5)$ & $54(47,60)$ & 0.672 & $51(48,58)$ & $48(44.5,56)$ & $0.254^{a}$ \\
\hline AHI & $22.05(18.6,25.35)$ & $56.05(40.6,84.3)$ & $<0.001^{*}$ & $20.4(18.8,23.2)$ & $57.15(42.7,76.6)$ & $<0.001^{* *}$ \\
\hline
\end{tabular}

${ }^{2}$ Mann-Whitney U test

${ }^{*} \mathrm{p}<0.01$

Table 2. Comparison of the prevalence of OAB, OAB-V8, and ICIQ-SF scores between OSA groups before and after CPAP therapy

\begin{tabular}{|c|c|c|c|c|c|c|}
\hline & \multicolumn{3}{|c|}{ Female $(n=28)$} & \multicolumn{3}{|c|}{ Male $(n=45)$} \\
\hline & Moderate & Severe & $\mathrm{p}$ & Moderate & Severe & $\mathrm{p}$ \\
\hline Severe and moderate OSA, $\mathrm{n}(\%)$ & $28(38.4)$ & & & $45(61.6)$ & & \\
\hline Prevalence of OAB, n (\%) & $23(82.1)$ & $19(67.9)$ & $0.046^{* \mathrm{~b}}$ & $29(64.4)$ & $23(51.1)$ & $0.014^{* \mathrm{~b}}$ \\
\hline OAB-V8, median (IQR) & $15.5(1219)$ & $9.5(712)$ & $<0.001^{* *_{c}}$ & $10(614)$ & $9(512)$ & $<0.001^{* *_{c}}$ \\
\hline ICIQ-SF score, median (IQR) & $0(07)$ & $0(06)$ & $0.033^{*_{c}}$ & $0(00)$ & $0(00)$ & $0.180^{c}$ \\
\hline Moderate OSA, n (\%) & $8(28.6)$ & & & $13(28.9)$ & & \\
\hline Prevalence of OAB, n (\%) & $6(75.0)$ & $5(62.5)$ & $0.317^{\mathrm{b}}$ & $5(38.5)$ & $4(30.8)$ & $0.317^{\mathrm{b}}$ \\
\hline OAB-V8, median (IQR) & $15(1016.5)$ & $9(711.5)$ & $0.035^{*_{c}}$ & $6(413)$ & $6(49)$ & $0.151^{\mathrm{c}}$ \\
\hline ICIQ-SF score, median (IQR) & $0(06)$ & $0(03)$ & $0.317^{c}$ & $0(00)$ & $0(00)$ & $0.058^{c}$ \\
\hline Severe OSA, n (\%) & $20(71.4)$ & & & $32(71.1)$ & & \\
\hline Prevalence of OAB, n (\%) & $17(85.0)$ & $14(70.0)$ & $0.083^{\mathrm{b}}$ & $24(75.0)$ & $19(59.4)$ & $0.025^{* \mathrm{~b}}$ \\
\hline OAB-V8, median (IQR) & $16(1221.5)$ & $10.5(712.5)$ & $<0.001^{* * c}$ & $12.5(714)$ & $10(612)$ & $<0.001^{* * c}$ \\
\hline ICIQ-SF score, median (IQR) & $0(0,8)$ & $0(0,7.5)$ & $0.999^{c}$ & $0(0,0)$ & $0(0,0)$ & $0.180^{c}$ \\
\hline Moderate vs. severe, n (\%) & $\mathrm{p}$ & $\mathrm{p}$ & & $\mathrm{p}$ & $\mathrm{p}$ & \\
\hline Prevalence of OAB, n (\%) & $0.606^{\mathrm{d}}$ & $0.999^{d}$ & & $0.037^{* d}$ & $0.082^{\mathrm{e}}$ & \\
\hline OAB-V8, median (IQR) & $0.258^{\mathrm{a}}$ & $0.672^{\mathrm{a}}$ & & $0.096^{\mathrm{a}}$ & $0.086^{\mathrm{a}}$ & \\
\hline ICIQ-SF score, median (IQR) & $0.381^{\mathrm{a}}$ & $0.636^{\mathrm{a}}$ & & $0.187^{\mathrm{a}}$ & $0.259^{a}$ & \\
\hline
\end{tabular}

${ }^{a}$ Mann-Whitney U test

${ }^{\mathrm{b}}$ Marginal homogeneity test

'Wilcoxon signed rank test

'Fisher's exact test

'Pearson chi-squared test

*p $<0.05$

*** $\mathrm{p}<0.01$ 
Table 3. Correlation between AHI scores and OAB-V8, and ICIQSF scores

\begin{tabular}{|c|c|c|c|c|}
\hline \multirow{3}{*}{$\begin{array}{l}\text { Before } \\
\text { CPAP } \\
\text { therapy }\end{array}$} & \multicolumn{4}{|c|}{ AHI } \\
\hline & \multicolumn{2}{|c|}{ Female } & \multicolumn{2}{|c|}{ Male } \\
\hline & $\mathbf{r}$ & $\mathrm{p}$ & $\mathbf{r}$ & $\mathrm{p}$ \\
\hline OAB-V8 & 0.516 & $0.005^{* *}$ & 0.325 & $0.029^{*}$ \\
\hline ICIQ-SF & 0.497 & $0.007^{* *}$ & 0.212 & 0.162 \\
\hline $\begin{array}{l}{ }^{*} \mathrm{p}<0.05 \\
*_{* *} \mathrm{p}<0.01 \\
\mathrm{r}: \text { Spearman }\end{array}$ & n coef & I: apnea- & index & \\
\hline
\end{tabular}

patients with severe OSA; however, there were no significant differences in the prevalence of OAB [5 patients (38.5\%) vs. 4 patients (30.8\%), p>0.05] or OAB-V8 median [6 (413) vs. 6 (49), $p>0.05]$ in patients with moderate OSA before and after CPAP therapy (Table 2). In addition, correlations between $\mathrm{AHI}$ and $\mathrm{OAB}-\mathrm{V} 8$ and ICIQ-SF were also explored, which revealed a positive correlation between $\mathrm{AHI}$ and $\mathrm{OAB}-\mathrm{V} 8$ $(\mathrm{r}=0.325, \mathrm{p}=0.029)($ Table 3$)$.

\section{Discussion}

This study showed that patients with moderate and severe OSA are more likely to present with $\mathrm{OAB}$ than the average population and that CPAP therapy improves the symptoms of $\mathrm{OAB}$ in both male and female patients. The prevalence of $\mathrm{OAB}$ in female patients with OSA was found to be higher than the reported population prevalence (12), and this prevalence significantly decreased after CPAP therapy. Moreover, OAB-V8 significantly decreased after CPAP therapy. Unlike in male patients, the ICIQ-SF scores significantly decreased after CPAP therapy. When female patients were investigated according to OSA severity, OAB-V8 was found to be significantly decreased after CPAP therapy in both moderate and severe OSA groups. Although there was a decrease in the prevalence of $\mathrm{OAB}$, this decrease was not statistically significant, which may be because of the small number of female patients in the moderate and severe OSA groups. No significant change was observed in the ICIQ-SF scores in both moderate and severe OSA groups. A comparison of the moderate and severe groups showed no significant differences. In addition, a positive correlation was observed between OSA severity and $\mathrm{OAB}-\mathrm{V} 8$ and ICIQ-SF scores.

Similar to the female patient group, the prevalence of OAB in male patients with OSA was higher than the reported population prevalence. The prevalence of $\mathrm{OAB}$ significantly decreased after CPAP therapy. CPAP therapy did not have any significant effect on the ICIQ-SF scores. When male patients were investigated according to OSA severity, OAB-V8 was found to be significantly decreased after CPAP therapy in both moderate and severe OSA groups. There was a significant difference in the prevalence of $\mathrm{OAB}$ only in patients with severe OSA. No significant change was detected in the ICIQ-SF scores in both moderate and severe groups. A comparison of the moderate and severe groups revealed no significant differences. In addi- tion, a positive correlation was observed between OSA severity and OAB-V8 but not between OSA severity and the ICIQ-SF scores.

Several questions regarding the relationship between bladder and sleep disorders remain, and the pathophysiological basis remains unclear. One theory is that OSA causes hypoxia-induced occult nerve dysfunction (13). Further, OSA is often observed in obese patients; thus, obesity may result in $\mathrm{OAB}$ through nerve dysfunction caused by reduced blood flow to the bladder (14).

More recently, Witthaus et al. (15) examined the bladder structure and function in a rat model of OSA and found that intermittent hypoxia in OSA induces oxidative stress with functional changes in the bladder of rats, leading to cystometric modifications that are characterized by increased spontaneous bladder contractions, noncompliance, and detrusor instability. According to these findings, OSA-related voiding problems may be associated with local changes in the bladder independent of urine production.

Consequently, the mechanism of OSA-induced OAB may be associated with hypoxia. Another potential theory is that the dysfunction of the central nervous system may contribute to sleep and urinary dysregulation because the hypothalamus regulates sleep and the pontine micturition center (14). The nocturia mechanism observed in these patients is related to respiratory tract obstruction. Airway obstruction contributes to increases in the negative intrathoracic pressure and in the venous blood flow to the heart. Volume expansion causes an increase in pressure, and subsequently atrial natriuretic peptide (ANP) is secreted by the cardiac ventricles and right atrium. ANP increases sodium and water excretion and suppresses vasopressin secretion and the renin-angiotensin-aldosterone complex. In conclusion, nocturia in patients with OSA is due to an excess nocturnal urine production (16). This relationship was also supported in human studies in which CPAP therapy was shown to increase oxygen saturation; decrease negative intrathoracic pressure, serum ANP levels, blood pressure, and sympathetic over activation; and improve the symptoms of $\mathrm{OAB}$ (17).

Ipekci et al. (4) studied 140 female patients with OSA and found an association between OSA and OAB, thereby reporting that CPAP therapy improves OAB, OAB-V8, and ICIQ-SF scores in women with severe and moderate OSA. Another sleep study with 71 male patients showed that patients with moderate and severe OSA presented with a significantly higher incidence of symptoms of OAB than did those with mild OSA and upper airway resistance syndrome (13). Miyauchi et al. (18) treated a group of male and female patients with OSA using CPAP therapy and reported that the nighttime urinary frequency decreases by reducing the volume of nocturnal urine. Miyazato et al. (19) enrolled 53 patients with moderate-to-severe OSA and an AHI of $>20 / \mathrm{h}$ and demonstrated that CPAP therapy decreases the nighttime urinary frequency by reducing the nocturnal urine production and improves the QoL. Our results support those 
of these previous studies that revealed an association between $\mathrm{OSA}$ and $\mathrm{OAB}$ and an improvement in the symptoms of $\mathrm{OAB}$ after CPAP therapy.

Although our data showed a strong correlation between OSA and $\mathrm{OAB}$, there are several limitations to this study. CPAP therapy for three months may be insufficient to completely restore oxidative damage. Therefore, further studies with longer CPAP therapy periods should be undertaken. Another limitation is the small sample size, particularly of the female patient group. Small sample sizes in both male and female groups may have led to the insignificant difference in the prevalence of $\mathrm{OAB}$ before and after CPAP therapy in both moderate and severe OSA groups despite the significant change in $\mathrm{OAB}-\mathrm{V} 8$. The strength of our study was the inclusion of a clinically relevant sample of patients recruited from a sleep disorders clinic.

\section{Conclusion}

Our findings suggest that CPAP therapy improves the clinical symptoms of OAB. Thus, unnecessary medical or interventional treatment of $\mathrm{OAB}$ can be avoided in such patients. Furthermore, these findings have a clinical indication that patients with refractory OAB should be referred to sleep clinics for PSG and untreated OSA. In addition, OAB should be investigated in patients with more severe OSA. An increased understanding of this complex relationship will lead to increasingly refined treatments for $\mathrm{OAB}$.

Ethics Committee Approval: Ethics committee approval was received for this study from the Ethics Committee of Gaziosmanpaşa Taksim Training and Research Hospital (Approval no: 12/10.06.2015).

Informed Consent: Written informed consent was obtained from patients who participated in this study.

Peer-review: Externally peer-reviewed.

Author Contributions: Concept - M.E.D., M.Ö.A., M.B.C.B., C.Ö.; Design - M.E.D., M.Ö.A., M.B.C.B., C.Ö.; Supervision - M.E.D., M.Ö.A., M.B.C.B., C.Ö.; Resource - M.E.D., M.B.C.B., C.Ö.; Materials - M.E.D., M.B.C.B., C.Ö.; Data Collection and/or Processing M.E.D., M.Ö.A., M.B.C.B.; Analysis and/or Interpretation - M.E.D., M.B.C.B., C.Ö.; Literature Search - M.Ö.A., C.Ö.; Writing - M.E.D.; Critical Reviews - M.E.D., M.Ö.A., M.B.C.B., C.Ö.

Conflict of Interest: The authors have no conflicts of interest to declare.

Financial Disclosure: The authors declared that this study has received no financial support.

\section{References}

1. Lee W, Nagubadi S, Kryger MH, Mokhlesi B. Epidemiology of obstructive sleep apnea: a population-based perspective. Expert Rev Respir Med 2008; 2: 349-64. [CrossRef]

2. Herrscher TE, Overland B, Sandvik L, Westheim AS, Akre H. High cardiovascular risk profile in patients with sleep apnea. Laryngoscope 2014; 124: 306-10. [CrossRef]
3. Kemmer H. The relationship between sleep apnea and overactive bladder. Curr Urol Rep 2009; 10: 448-50. [CrossRef]

4. Ipekci T, Cetintas G, Celik O, Ekin RG, Sarac S, Tunckiran A, et al. Continuous positive airway pressure therapy is associated with improvement in overactive bladder symptoms in women with obstructive sleep apnea syndrome. Cent European J Urol 2016; 69: 78-82.

5. Abrams P, Cardozo L, Fall M, Griffiths D, Rosier P, Ulmsten U, et al. The standardisation of terminology of lower urinary tract function: report from the Standardisation Sub-committee of the International Continence Society. Neurourol Urodyn 2002; 21: 167-78. [CrossRef]

6. Shy M, Fletcher SG. Objective evaluation of overactive bladder: Which surveys should I use? Curr Bladder Dysfunct Rep 2013; 8: 45-50. [CrossRef]

7. Guo J, Sun Y, Xue LJ, Huang ZY, Wang SY, Zhang L, et al. Effect of CPAP therapy on cardiovascular events and mortality in patients with obstructive sleep apnea: a meta-analysis. Sleep Breath 2016; 20: 965-74. [CrossRef]

8. Berry RB, Budhiraja R, Gottlieb DJ, Gozal D, Iber C, Kapur VK, et al. Rules for scoring respiratory events in sleep: update of the 2007 AASM Manual for the Scoring of Sleep and Associated Events. Deliberations of the Sleep Apnea Definitions Task Force of the American Academy of Sleep Medicine. J Clin Sleep Med 2012; 8: 597-619.

9. Tarcan T,Mangir N, Özgür MO, Akbal C. OAB-V8 Overactive Bladder Questionnaire Validation Study. Üroloji Bülteni 2012; 21: 113-6.

10. Çetinel B, Özkan B, Can G. The validation study of ICIQ-SF Turkish version. Turkish J Urol 2004; 30: 332-8.

11. Barry MJ, Fowler FJ Jr, O'Leary MP, Bruskewitz RC, Holtgrewe HL, Mebust WK, et al. The American Urological Association symptom index for benign prostatic hyperplasia. The Measurement Committee of the American Urological Association. J Urol 1992; 148: 1549-57. [CrossRef]

12. Irwin DE, Milsom I, Hunskaar S, Reilly K, Kopp Z, Herschom S, et al. Population-based survey of urinary incontinence, overactive bladder, and other lower urinary tract symptoms in five countries: results of the EPIC study. Eur Urol 2006; 50: 1306-14. [CrossRef]

13. Kemmer H, Mathes AM, Dilk O, Gröschel A, Grass C, Stöckle M. Obstructive sleep apnea syndrome is associated with overactive bladder and urgency incontinence in men. Sleep 2009; 32: 271-5. [CrossRef]

14. Tsujimura A, Takao T, Miyagawa Y, Yamamoto K, Fukuhara S, Nakayama J, et al. Urgency is an independent factor for sleep disturbance in men with obstructive sleep apnea. Urology 2010; 76: 967-70. [CrossRef]

15. Witthaus MW, Nipa F, Yang JH, Li Y, Lerner LB, Azadzoi KM. Bladder oxidative stress in sleep apnea contributes to detrusor instability and nocturia. J Urol 2015; 193: 1692-9. [CrossRef]

16. Ljunggren M, Lindahl B, Theorell HJ, Lindberg E. Association between obstructive sleep apnea and elevated levels of type B natriuretic peptide in a community-based sample of women. Sleep 2012; 35: 1521-7. [CrossRef]

17. Margel D, Shochat T, Getzler O, Livine PM, Pillar G. Continuous positive airway pressure reduces nocturia in patients with obstructive sleep apnea. Urology 2006; 67: 974-7. [CrossRef]

18. Miyauchi Y, Okazoe H, Okujyo M, Inada F, Kakehi T, Kikuchi $\mathrm{H}$, et al. Effect of the continuous positive airway pressure on the nocturnal urine volume or night-time frequency in patients with obstructive sleep apnea syndrome. Urology 2015; 85: 333-6. [CrossRef] 
19. Miyazato M, Tohyama K, Touyama M, Nakamura H, Oshiro T, Ueda S, et al. Effect of continuous positive airway pressure on noc- turnal urine production in patients with obstructive sleep apnea syndrome. Neurourol Urodyn 2017; 36: 376-9. [CrossRef] 